\title{
The Mozart effect in biofeedback visual rehabilitation: a case report
}

This article was published in the following Dove Press journal:

Clinical Ophthalmology

3 September 201 I

Number of times this article has been viewed

\section{Serena Salvatore \\ Aloisa Librando \\ Mariacristina Esposito \\ Enzo MVingolo}

Department of Ophthalmology, University La Sapienza, Polo Pontino, Alfredo Fiorini Hospital, Terracina, Italy
Correspondence: Serena Salvatore Via Terni 38 EI3, 00I82 Rome, Italy Tel +39333 273I58I

Email serena.sal@hotmail.it
Purpose: To evaluate the usefulness of acoustic biofeedback by means of Mozart's Sonata for Two Pianos in D Major K. 448 to maintain and/or restore visual performance in a patient with macular pucker and glaucoma.

Methods: A 74-year-old patient with open angle glaucoma in both eyes and macular pucker in the right eye (RE) underwent visual rehabilitation with acoustic biofeedback by means of the MAIA $^{\text {TM }}$ Vision Training Module (Centervue, Padova, Italy) 10 minutes each eye once a week for 5 weeks. The patient was asked to move his eyes according to a sound which changed into Mozart's Sonata for Two Pianos when the patient locked the fixation target.

Results: Best-corrected visual acuity improved in his right eye (RE) and was stable in the left eye (LE). Fixation stability improved in both eyes, and retinal sensitivity decreased in the RE and improved in the LE. The characteristic of the macular pucker did not change during the training as demonstrated with optical coherence tomography. The patient was very satisfied with the training, as demonstrated by a 25-item questionnaire (National Eye Institute - Visual Functioning Questionnaire, NEI-VFQ-25). The patient's reading speed and the character size which he was able to read improved in his RE.

Conclusion: Music could enhance synaptic plasticity and affect neural learning and fixation training by means of MAIA vision training. Therefore it can improve visual performance in patients with macular pucker, postpone the surgical time, and assure a better quality of life for the patient.

Keywords: glaucoma, macular cellophane, music, vision training

\section{Introduction}

Techniques of biofeedback have been used for over a quarter of a century to train subjects to alter brain activity, blood pressure, muscle tension, heart rate, and other bodily functions that are not normally controlled voluntarily. In ophthalmology, various techniques of biofeedback, such as plain light stimulus, ${ }^{1}$ acoustic biofeedback, ${ }^{2}$ and structured light stimulus plus acoustic biofeedback ${ }^{3}$ have been applied to congenital nistagmus, ${ }^{4}$ amblyopia, ${ }^{5,6}$ macular disease, ${ }^{7}$ and emianopia ${ }^{8,9}$ and have proved to be efficacious in the improvement of visual function in these disorders. In 1993, Rauscher et $\mathrm{al}^{10}$ found that listening to Mozart music could improve the IQ (intelligence quotient) score of students, as opposed to listening to relaxation instructions or silence. More scientific studies on music have been conducted in recent years, mainly in the field of neuroscience, and the level of interest among researchers is increasing. ${ }^{11,12}$ The results of past studies have clarified that music influences and affects cranial nerves in humans from fetus to adult. ${ }^{13}$ The most important discovery by such studies has been that music 
enhances synaptic plasticity in the brain. Studies comparing musicians to nonmusicians and music learners to nonlearners have demonstrated that music brings about cerebral plasticity. Music affects neuronal learning and readjustment (response of brain cells to sound and music stimuli, and changes in cell counts), and this effect lasts for a long period of time. ${ }^{13}$ In this study we wanted to evaluate the usefulness of acoustic biofeedback by means of Mozart's Sonata for Two Pianos in D Major K. 448 to maintain and/or restore visual performance in a patient with macular pucker and glaucoma.

\section{Methods}

A 74-year-old Caucasian patient with open angle glaucoma in both eyes and macular pucker in the right eye (RE) underwent a visual rehabilitation with acoustic biofeedback by means of the MAIA TM Vision Training Module (Centervue, Padova, Italy). The patient underwent a rehabilitation protocol, which consisted of the following.

- A 25-item questionnaire (National Eye Institute-Visual Functioning Questionnaire, NEI- VFQ-25).

- Measurement of distant and best-corrected visual acuity (BCVA). Early Treatment of Diabetic Retinopathy Study tables were used. BCVA was determined at $30 \mathrm{~cm}$ with an appropriate addition. Visual acuity was expressed in logMAR (logarithm of minimum angle of resolution).

- A reading speed test. The reading speed for each eye was measured by reading black letters on a white background (Times New Roman font) at a distance of $30 \mathrm{~cm}$ of distance with an appropriate addition for age. The subject was asked to read aloud as quickly as possible without skipping words (the character size has been adapted to the patient's visual acuity and was measured in electronic points). The sentences contained words that occur frequently in Italian and had no punctuation.

- Microperimetry with MAIA. Threshold macular sensitivity and fixation stability were determined with the MAIA device. MAIA is a nonmydriatic, near-infrared, line-scanning, laser ophthalmoscope, which incorporates a high-frequency eye tracker and an automated threshold fundus perimeter. The automated eye tracker locks onto the entire fundus image and captures fixation changes 25 times per second during testing. The software also identifies the preferred retinal locus - a retinal position that identifies the patient's preferred fixation site. An automated retinal sensitivity program using Goldmann III stimuli size on a grid of 37 stimuli covering an area of 10 degrees centered on the patient's preferred retinal location (PRL); a 4-2 staircase strategy and stimulus intensity ranging from 0 to $36 \mathrm{~dB}$, where $0 \mathrm{~dB}$ represents the brightest luminance of 1000 asb over a background luminosity of 4 asb with a patient fixation target circle of $1^{\circ}$ diameter was used for the fixation and sensitivity test before and after the training.

- Five training sessions of 10 minutes for each eye were performed once a week using MAIA. The first step of the training was the selection of the PRL to be trained. The patient was then instructed to move his eyes according to a monotone sound (which uses only a note) which changed into Mozart's Sonata for Two Pianos when the patient locked the fixation target within the $2^{\circ}$ diameter circle centered on the fixation point.

- After 5 weeks of training, the patient was again subjected to the measurement of visual acuity, spectral domain optical coherence tomography (SD-OCT) with Cirrus SD-OCT (Carl Zeiss Meditec, Dublin, CA), retinal imaging with Nidek F10 (Nidek, Gamagori, Japan), reading speed test, fixation test, and microperimetry in the same manner as described above. Microperimetry was repeated with a follow-up feature that allows us to retest the same points of reference.

\section{Results}

BCVA was 0.52 $\log M A R$ in the RE and 0.09 in the LE, retinal sensitivity was $8.3 \mathrm{~dB}$ in the RE and $24.1 \mathrm{~dB}$ in the LE, bivariate contour ellipse area (BCEA) which contained $63 \%$ of the fixation points was 0.5 square retinal degrees (sq.ret.deg.) in the RE and 2.2 sq.ret.deg. in the LE before the training, and BCEA which contained $95 \%$ of the fixation points was 4.5 sq. ret.deg. in the RE and 19.7 sq.ret.deg. in the LE before the training. BCVA was $0.04 \log \mathrm{MAR}$ in the RE and 0.09 in the LE, retinal sensitivity was $6.2 \mathrm{~dB}$ in the RE and $22.5 \mathrm{~dB}$ in the LE, BCEA which contained $63 \%$ of the fixation points was 0.1 sq.ret.deg in the RE and 0.3 sq.ret.deg in the LE, and BCEA which contained $95 \%$ of the fixation points was 0.9 sq. ret.deg in the RE and 2.4 sq.ret.deg in the LE after the training (Figure 1). The characteristic of the macular pucker did not change during the training as demonstrated with OCT. The patient was very satisfied, and quality of life (patients' difficulties in activities and responses to vision problems) improved with the training, as demonstrated by NEI-VFQ-25. Baseline results with the NEI-VFQ-25 were for Part 1 (general health and vision), 8 points; Part 2 (difficulties with activities), 38 points; and Part 3 (responses to vision problems), 32 points. After biofeedback rehabilitation with MAIA, results with the NEI-VFQ-25 were for Part 1 (general health and vision), 6 points; Part 2 (difficulties with activities), 27 points; and 

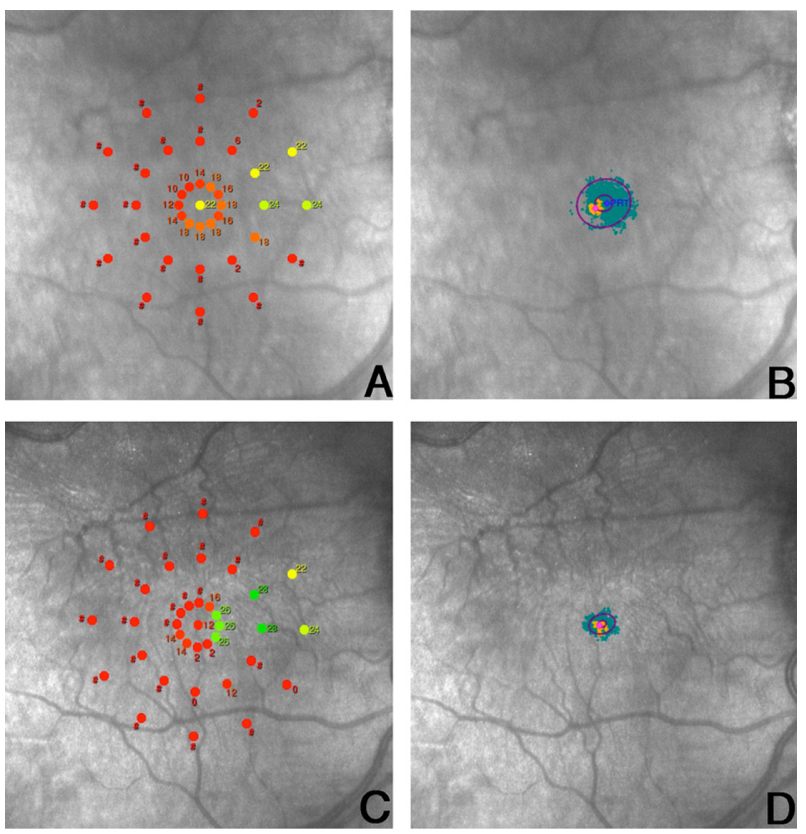

Figure I (A) Retinal sensitivity map before the training in patient's RE. (B) Fixation behavior represented by BCEA before training in patient's RE. (C) Retinal sensitivity fixation map of the patient's RE after the training. (D) Fixation behavior represented by $B C E A$ after the training in patient's RE. The figure shows a dramatic improvement in patient fixation behavior, which was strongly correlated with BCVA improvement and patient satisfaction after the acoustic biofeedback training.

Abbreviations: BCEA, bivariate contour ellipse area; BCVA, best-corrected visual acuity; RE, right eye.

Part 3 (responses to vision problems), 40 points. Before rehabilitation, the character size that the patient was able to read was 10 electronic points with his RE and 6 with his LE; after rehabilitation, the patient was able to read 6 electronic points with his RE and 6 with his LE. Reading speed after rehabilitation improved from 78 to 176 words/minute with his RE and 174 to 206 words/minute with his LE.

\section{Conclusion}

Although there was no improvement in total retinal sensitivity, except a slight improvement in the area of the selected PRL for training, the improvement in fixation stability in the patient's RE with macular pucker proved to be useful in restoring the patient's sight; BCVA improved from 0.52 to $0.04 \log \mathrm{MAR}$, and the patient was very satisfied with the training. The LE had two preferred retinal locations, with one reinforced to maintain BCVA stable. To the extent of the authors' knowledge, this is the first time that biofeedback training has been applied to macular pucker.

Macular diseases are ocular pathologies that affect the central retinal area, causing a reduction in visual acuity, contrast sensitivity, color perception, ocular motility, and altered stereopsis, and are accompanied by the appearance of scotomata in the visual field and visual impairment.
The improvement was probably due to the fact that we trained a "retinal motor" PRL with appropriate retinal sensitivity to increase the number of correct fixation saccades and re-reference the oculomotor system. ${ }^{14,15}$

Furthermore, sound perception increases the conscious attention of the patient, ${ }^{14-16}$ thereby facilitating the "locking in" of the visual target and increasing the permanence time of the target itself on the retina. This mechanism probably facilitates stimuli transmission between intraretinal neurons as well as between the retina and brain, where the highest degree of stimuli processing takes place, thereby supporting a "remapping phenomenon." Although cortical rearrangement with the resulting filling-in may play an important role in the training of a PRL, this can happen for a variety of reasons. This is the first time that Mozart music has been applied to a visual rehabilitation, and the results are worthy of attention. Music could enhance synaptic plasticity in the brain and affect neural learning and fixation training. By means of MAIA, we can improve the visual performance in patients with macular pucker to postpone the surgical time and assure the patient a better quality of life.

Further studies with large groups of patients are warranted to evaluate the usefulness of this new approach to treat macular pucker and other retinal diseases.

\section{Disclosure}

The authors report no conflicts of interest in this work.

\section{References}

1. Contestabile MT, Recupero SM, Palladino D, et al. A new method of biofeedback in the management of low vision. Eye. 2002;16(4): 472-480.

2. Vingolo EM, Cavarretta S, Domanico D, Parisi F, Malagola R. Microperimetric biofeedback in AMD patients. Appl Psychophysiol Biofeedback. 2007;32(3-4):185-189.

3. Vingolo EM, Salvatore S, Grenga PL, Limoli P. Visual training in retinitis pigmentosa patients: neural plasticity and function recovery. In: Catlin RB, ed. Retinal Degeneration: causes, diagnosis and treatment. New York: Nova Publisher; 2009:249-261.

4. Mezawa M, Ishikawa S, Ukai K. Changes in waveform of congenital nystagmus associated with biofeedback treatment. Br J Ophthalmol. 1990;74(8):472-476.

5. Rinaldi G, Iaconi P, Vattovani O, Spasse S, Canziani T, Ravalico G Treatment with visual pathfinder in a child affected by bilateral corioretinal coloboma. Invest Opthalmol Vis Sci. 2003;44:E-Abstract 1950.

6. Iacono $\mathrm{P}$, Vattovani $\mathrm{O}$, Rinaldi $\mathrm{G}$, et al. Visual training in anisometropic amblyopic children monitored with visual pathfinder system. Invest Ophthalmol Vis Sci. 2003;44:E-Abstract 4796.

7. Vingolo EM, Salvatore S, Cavarretta S. Low-vision rehabilitation by means of MP-1 biofeedback examination in patients with different macular diseases: a pilot study. Appl Psychophysiol Biofeedback. 2009; 34(2):127-133.

8. Henriksson L, Raninen A, Näsänen R, Hyvärinen L, Vanni S. Traininginduced cortical representation of a hemianopic hemifield. $J$ Neurol Neurosurg Psychiatry. 2007;78(1):74-81. 
9. Raninen A, Vanni S, Hyvarinen, Nasanen R. Temporal sensitivity in a hemianopic visual field can be improbe by long-term training using flicker stimulation. J Neurol Neurosurg Psychiatry. 2007;78(1):66-73.

10. Rauscher FH, Shaw GL, Ky KN. Music and spatial task performance. Nature. 1993;365(6447):611.

11. Zatorre RJ. Music and the brain. Ann NY Acad Sci. 2003;999:4-14.

12. Zatorre R, McGill J. Music, the food of neuroscience? Nature. 2005; 434(7031):312-315.

13. Abbott A. Music, maestro, please. Nature. 2002;416(6876):12-14.
14. Alpeter E, Mackben M, Trauzettel-Klosinski S. The importance of sustained attention for patients with maculopathies. Vision Res. 2000;40(10-12):1539-1547.

15. Schuchard RA. Preferred retinal loci and macular scotoma characteristics in patients with age-related macular degeneration. Can $J$ Ophthalmol. 2005;40(3):303-312.

16. Buia $\mathrm{C}$, Tiesinga $\mathrm{P}$. Attentional modulation of firing rate and synchrony in a model cortical network. J Comput Neurosci. 2006;20(3):247-264.
Clinical Ophthalmology

\section{Publish your work in this journal}

Clinical Ophthalmology is an international, peer-reviewed journal covering all subspecialties within ophthalmology. Key topics include: Optometry; Visual science; Pharmacology and drug therapy in eye diseases; Basic Sciences; Primary and Secondary eye care; Patient Safety and Quality of Care Improvements. This journal is indexed on

\section{Dovepress}

PubMed Central and CAS, and is the official journal of The Society of Clinical Ophthalmology (SCO). The manuscript management system is completely online and includes a very quick and fair peer-review system, which is all easy to use. Visit http://www.dovepress.com/ testimonials.php to read real quotes from published authors. 